\title{
Influence of defects on the irreversible phase transition in the Fe-Pd doped with Co and Mn
}

\author{
Federico Guillermo Bonifacich ${ }^{1}$, Osvaldo Agustín Lambri ${ }^{1}$, \\ Damián Gargicevich $^{1}$, Griselda Irene Zelada ${ }^{1}$, José Ignacio Pérez-Landazábal ${ }^{2,3}$, \\ Vicente Recarte ${ }^{2,3}$, Vicente Sánchez-Alarcos 2,3
}

\author{
${ }^{1}$ CONICET-UNR-Laboratorio de Materiales, Escuela de Ingeniería Eléctrica, Centro de Tecnología e Investigación \\ Eléctrica, Facultad de Ciencias Exactas, Ingeniería y Agrimensura, Avda. Pellegrini 250, CP: 2000, Rosario, Santa Fe, \\ Argentina. \\ e-mail: bonifaci@fceia.unr.edu.ar; olambri@fceia.unr.edu.ar; gargi@fceia.unr.edu.ar; gizelada@fceia.unr.edu.ar \\ ${ }^{2}$ Departamento de Física, Universidad Pública de Navarra, Campus de Arrosadía 31006, Pamplona, Navarra, Spain. \\ ${ }^{3}$ Institute for Advanced Materials (INAMAT), Universidad Pública de Navarra, \\ Campus de Arrosadía 31006, Pamplona, Navarra, Spain. \\ e-mail: ipzlanda@unavarra.es; recarte@unavarra.es; vicente.sanchez@unavarra.es
}

\begin{abstract}
The appearance of BCT martensite in Fe-Pd-based ferromagnetic shape memory alloys, which develops at lower temperatures than the thermoelastic martensitic transition, deteriorates the shape memory properties. In a previous work performed in $\mathrm{Fe}_{70} \mathrm{Pd}_{30}$, it was shown that a reduction in defects density reduces the non thermoelastic FCT-BCT transformation temperature. In the present work, the influence of quenched-indefects upon the intensity and temperature of the thermoelastic martensitic (FCC-FCT) and the non thermoelastic (FCT-BCT) transitions in Fe-Pd doped with Co and Mn is studied. Differential scanning calorimetric and mechanical spectroscopy studies demonstrate that a reduction in the dislocation density the stability range of the FCC-FCT reversible transformation in $\mathrm{Fe}_{67} \mathrm{Pd}_{30} \mathrm{Co}_{3}$ and $\mathrm{Fe}_{66.8} \mathrm{Pd}_{30.7} \mathrm{Mn}_{2.5}$ ferromagnetic shape memory alloys.
\end{abstract}

Keywords: Fe-Pd-Co; Fe-Pd-Mn; ferromagnetic shape memory alloys; martensitic transformation; dislocation dynamics.

\section{INTRODUCTION}

Ferromagnetic shape memory alloys (FSMA) have attracted much scientific and technological interest owing to a broad range of possible engineering applications. These functional materials have the unique properties they show as a result of the combination of a thermoelastic martensitic transformation (MT) and a magnetic transition. In fact, one of the most interesting properties is the high magnetoplasticity they show as a consequence of the magnetic field induced re-orientation of the magnetic martensitic variants. In addition, fundamental physics studies related to the coupling between structural, mechanical, magnetic and thermodynamic properties are field of intense work [1,2]. Concerning the Fe-Pd system, the face centered tetragonal (FCT) martensitic phase allows the magnetic shape memory effect by reorientation of martensite variants via twin boundary motion. The FCT martensite can be obtained when cooling face centered cubic (FCC) austentite through the MT in samples which were quenched in iced water after an annealing at $1173 \mathrm{~K}$ [3-5]. This structural transformation from FCC to FCT only takes place in a very narrow compositional range $(29<$ at\% $\mathrm{Pd}<32)$ and the transformation temperatures lie typically below room temperature $(\mathrm{RT})[6,7]$. At lower temperature an irreversible transformation (FCT-BCT) needs to be prevented in order to retain the shape memory properties [8-12]. These temperatures strongly depend on both the composition and the addition of a third element. In fact, in previous works, the partial substitution of Fe by Co and Mn on the structural and magnetic properties of Fe-Pd alloys has been investigated and MT temperatures dependence has been observed [13,14]. Moreover, it was a reported that with some specific concentration of $\mathrm{Mn}$ it is possible to prevent the FCT-BCT non-thermoelastic MT [14].

Nevertheless, there exist other different contributions like internal stresses, point defects, dislocations and other bi-, tri-dimensional microstructural defects that could play an important role in the characteristics 
of these phase transformations and in their stabilities [15-17]. Indeed, in a recent work the influence of defects on the FCT-BCT transition temperature has been studied. The large misfit between the cell parameters of FCT and BCT martensites point out to a critical role of dislocations in the accommodation of these phases. In this sense, mechanical spectroscopy which is a powerful and sensitive technique to analyze the dynamics of structural defects like dislocations was used [18,19].

The aim of the present work is to study the role of quenched-in-defect on the FCC-FCT and FCT-BCT transformations temperatures in Fe-Pd ferromagnetic shape memory alloys doped with Co and Mn by means of mechanical spectroscopy and differential calorimetry studies.

\section{MATERIALS AND METHODS}

Polycrystalline ingots of nominal composition (at.\%) $\mathrm{Fe}_{67} \mathrm{Pd}_{30} \mathrm{Co}_{3}$ and $\mathrm{Fe}_{66.8} \mathrm{Pd}_{30.7} \mathrm{Mn}_{2.5}$ were prepared from high purity elements by arc melting under protective Ar atmosphere (called hereafter FePdCo and FePdMn). Ingots were homogenized in vacuum at $1273 \mathrm{~K}$ during 24 hours, and subsequently they were subjected to a 30 minutes annealing treatment at $1173 \mathrm{~K}$ in a vertical furnace; followed by quenching into iced water under vacuum. The compositions of the alloys were analyzed by energy dispersive X-ray spectroscopy (EDS) in a Jeol JSM-5610LV scanning electron microscope (SEM).

Differential scanning calorimetry (DSC) measurements were carried out at a heating/cooling rate of $10 \mathrm{~K} / \mathrm{min}$ in a TA Q100 calorimeter under nitrogen protective atmosphere. Different thermal cycles, involving heating and cooling runs, with different both minimum and maximum temperatures, within the interval around $150 \mathrm{~K}$ and $723 \mathrm{~K}$, were performed in order to induce or prevent the non-thermoelastic MT. For $\mathrm{Fe}_{67} \mathrm{Pd}_{30} \mathrm{Co}_{3}$ were performed eight thermal cycles and for $\mathrm{Fe}_{66.8} \mathrm{Pd}_{30.7} \mathrm{Mn}_{2.5}$ were performed nine thermal cycles.

During the mechanical spectroscopy (MS) studies the simultaneous measurement of damping, $Q^{-1}$ (or internal friction) and natural frequency $\left(f, f^{2}\right.$ being proportional to the shear elastic modulus) as a function of temperature were performed $[18,20]$.

MS measurements were performed in a mechanical spectrometer based on an inverted torsion pendulum, assembled in the laboratory, under Ar at atmospheric pressure. The schematic representation of the experimental device is presented in Figure 1 taken from Ref. [21]. The maximum strain on the sample surface was $5 \times 10^{-5}$. The measurement frequency was around $1 \mathrm{~Hz}$. The heating and cooling rates employed in the tests were $1 \mathrm{~K} /$ minute. Damping was calculated from the slope of the natural logarithm of the decaying amplitudes versus period number through equation (1), such that [18]

$$
\ln \left(A_{n}\right)=\ln \left(A_{0}\right)-n \pi Q^{-1}
$$

where $A_{n}$ is the area of the $n^{\text {th }}$ decaying oscillation, $A_{0}$ is the initial area of the starting decaying oscillation and $\mathrm{n}$ is the period number. For all these measurements the same initial and final values of the decaying amplitudes were used to avoid distortions linked to the appearance of amplitude dependent damping effects [20]. In order to study the presence of non-linear effects in the microstructure, amplitude dependent damping (ADD), i.e. damping as a function of the maximum strain on the sample, $\varepsilon_{0}$, was calculated from equation (2) [20,22]:

$$
Q^{-1}\left(\varepsilon_{0}\right)=-\frac{1}{\pi} \frac{d\left(\ln \left(A_{n}\right)\right)}{d n}
$$

Polynomials were fitted to the curve of the decaying areas of the torsional vibrations as a function of the period number by means of Chi-square fitting. Polynomials of degree higher than 1 indicate that $Q^{-1}$ is a function of $\varepsilon_{0}$, leading to the appearance of ADD effects, as it can be inferred easily. Subsequently the equation (2) was applied. This procedure allows to obtain damping as a function of the maximum strain $\left(\varepsilon_{0}\right)$ from free decaying oscillations [20,22]. The strength of the ADD, can be determined through the average slope of the $Q^{-1}\left(\varepsilon_{0}\right)$ curve using the $\mathrm{S}$ coefficient in equation (3) [20,22]:

$$
S=\frac{\Delta Q^{-1}}{\Delta \varepsilon_{0}}
$$

where $\Delta Q^{-1}$ is the damping change corresponding to the full amplitude changes $\Delta \varepsilon_{0}$ measured in the whole oscillating strain range. 


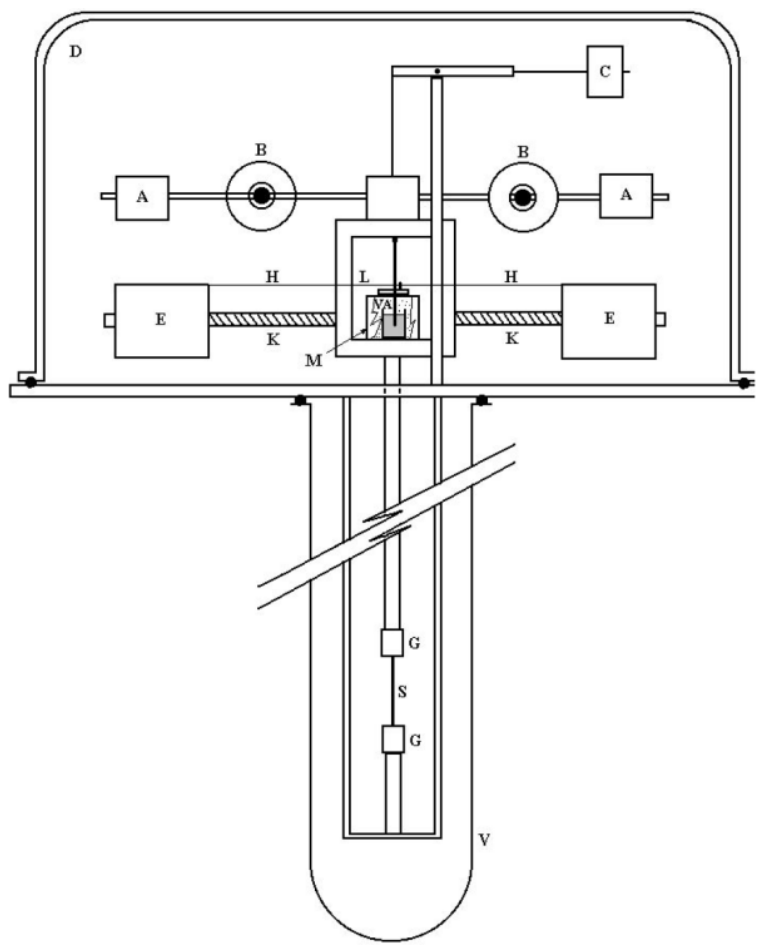

Figure 1: Schematic representation of the experimental device used during mechanical spectroscopy measurement. S: sample. G: jaws B: excitation coils. E: masses for variable moment of inertia. Taken from Ref. [21].

\section{RESULTS AND DISCUSSION}

The thermoelastic martensitic transformation (MT) has been studied firstly by DSC measurement. Figure 2 shows the DSC thermograms for FePdCo (a) and FePdMn (b) alloys, in the as-quenched state, from a temperature higher than the non-thermoelastic MT up to different maximum temperatures. In fact, the minimum temperature during the DSC measurements was $220 \mathrm{~K}$ and $273 \mathrm{~K}$ in order to prevent the nonthermoelastic MT in for FePdCo and FePdMn alloys, respectively. The exothermic (endothermic) peak observed on cooling (heating) corresponds to a direct (reverse) thermoelastic MT. Thermoelastic MT occurs at $260 \mathrm{~K}$ and $310 \mathrm{~K}$ for FePdCo and FePdMn, respectively. The MT temperature was obtained as the reaction peak temperature, i.e. MT temperature peak. The measured enthalpies are $0.8 \mathrm{~J} / \mathrm{g}$ and $0.7 \mathrm{~J} / \mathrm{g}$ for FePdCo and FePdMn, respectively $[14,23,24]$. The Curie temperatures can be observed thorough the change in the baseline at $\mathrm{T}_{\mathrm{C}}=603 \mathrm{~K}$ for FePdCo and $\mathrm{T}_{\mathrm{C}}=540 \mathrm{~K}$ for FePdMn [13,24].

After several thermal cycles up to different maximum temperatures, appreciable changes in the height and temperature of the MT from DSC thermograms were not detected [25]. A change in less than $3 \mathrm{~K}$ for the MT temperature was detected in the two alloys.

On further cooling a non-thermoelastic (FCT-BCT) transformation takes place. In fact, thermograms shown in Figure 3 were performed at temperatures lower than the non-thermoelastic MT temperature. These thermograms show a series of peaks which correspond to the FCT-BCT transformation in FePdCo alloy. The approximate temperatures for the appearance of the non-thermoeleastic MT were $190 \mathrm{~K}$ and $240 \mathrm{~K}$ for FePdCo and FePdMn, respectively $[13,14,25,26]$. The FCT-BCT transformation is non-thermoelastic and the appearing BCT phase will remain (degrading the shape memory properties) unless the alloy is annealed at high temperature and subsequently quenched [6].

At temperatures lower than the non-thermoelastic transition both the reversible and the irreversible phases coexist. In this way, it is expected that the different cell parameters of the FCT phase and the BCT phase could be generate internal stresses in the alloy. In fact, it has been reported that in (at.\%) $\mathrm{Fe}_{70} \mathrm{Pd}_{30}$ the large misfit between both phases, revealed by means neutron thermodiffraction measurements, must be adjusted by the creation of dislocations or twins boundaries to relief the stresses generated in the interphase area. Then the larger the quantity of dislocations in the alloy, the easier should be the irreversible transition to the BCT phase. So it could be expected that a low density of dislocations must produce a reduction in the transition temperature [25]. 

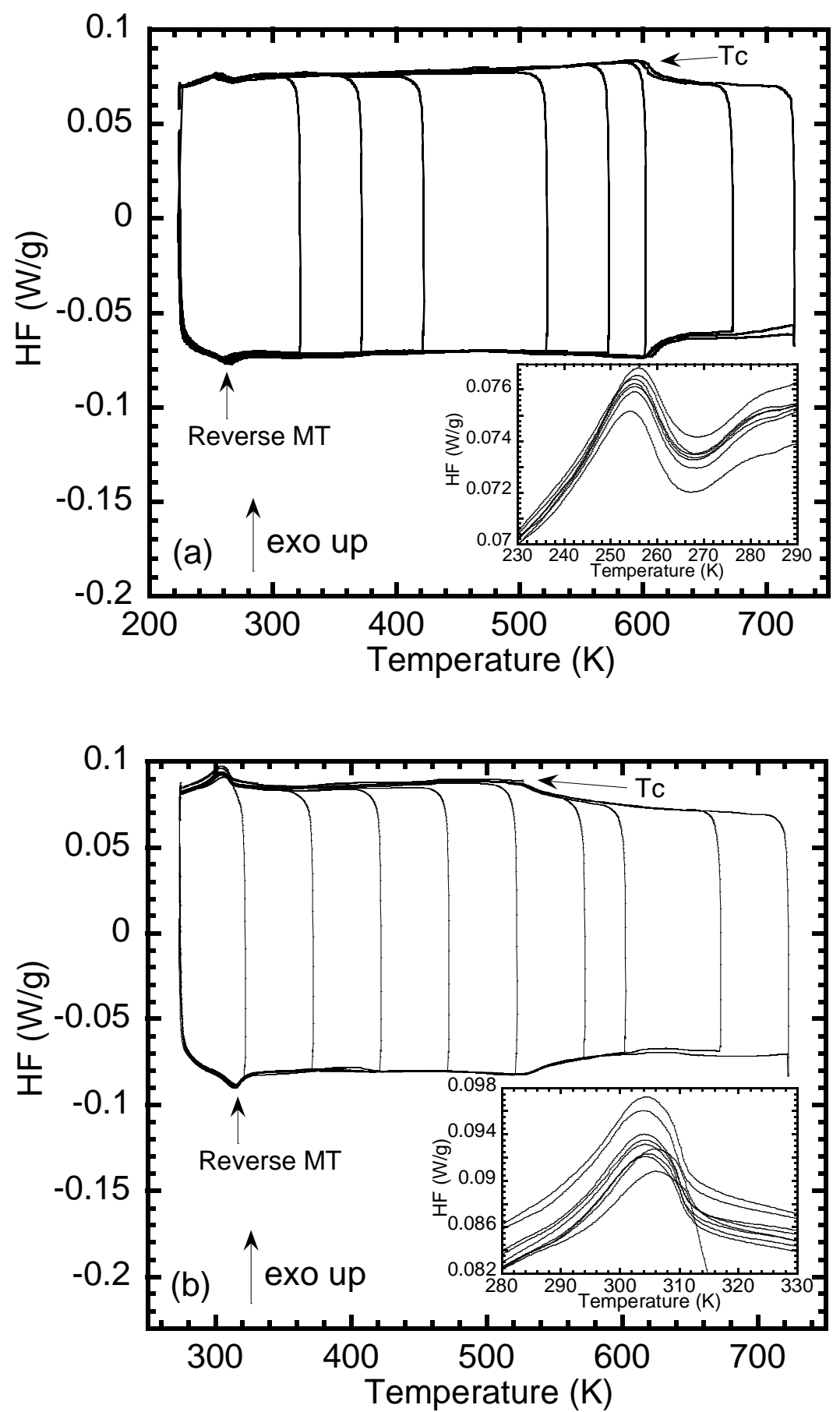

Figure 2: Heat flux (HF) as a function of temperature during the DSC measurement for (a) FePdCo and (b) FePdMn from a temperature higher than the non-thermoelastic MT temperature up to different maximum temperatures. Arrows indicate the MT and Tc temperatures. The inset shows a magnification of the MT temperature range. 


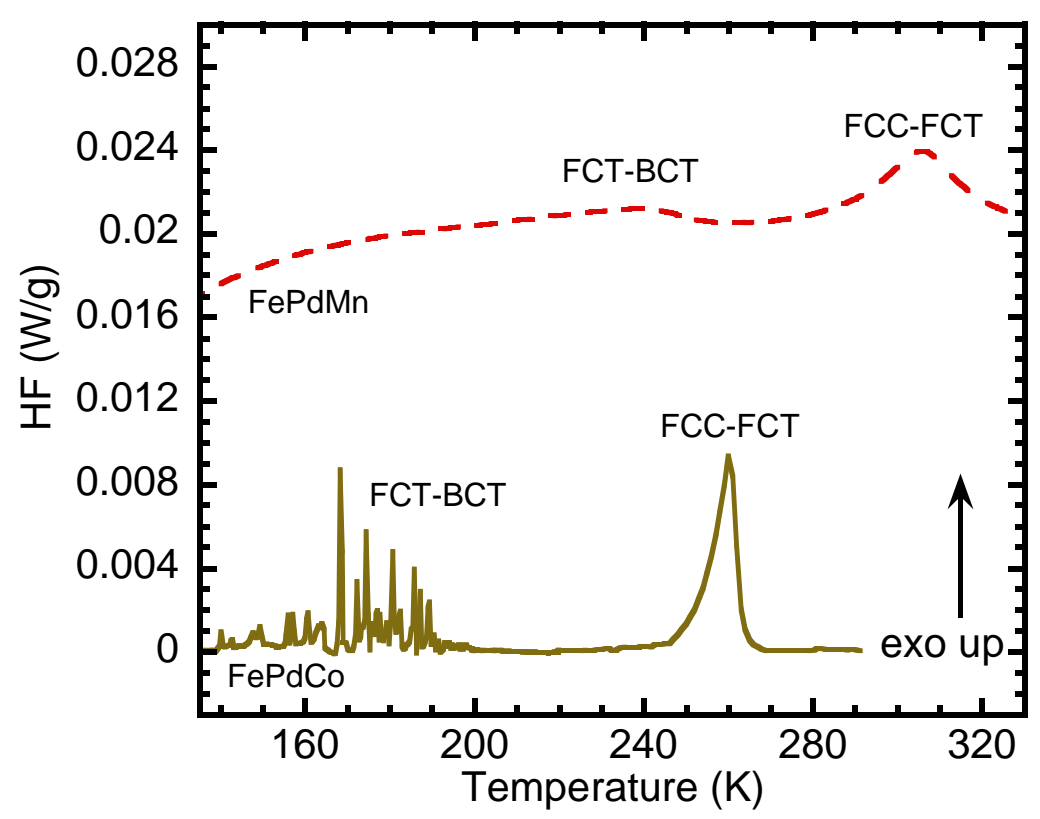

Figure 3: DSC thermograms performed down to temperatures lower than the non-thermoelastic transformation temperature for FePdCo and FePdMn.

In order to study the influence of the non-thermoelastic MT on thermoelastic MT, mechanical spectroscopy measurement from temperatures below the FCT-BCT transformation temperature were carried out. Figures 4 and 5 show the damping spectra and squared frequency (proportional to shear elastic modulus) curves, from $170 \mathrm{~K}$ up to different maximum temperatures, for FePdCo and FePdMn alloys, respectively. The maximum temperature reached in each consecutive thermal cycle was increased as follows: $603 \mathrm{~K}, 603 \mathrm{~K}$, $673 \mathrm{~K}, 773 \mathrm{~K}$ and $773 \mathrm{~K}$. In Figures 4(a) and 5(a) a damping peak at around $450 \mathrm{~K}$ can be observed during the successive thermal cycles. During the second heating run up to the same temperature of the first, this peak decreases its height markedly in both alloys. In fact, this peak has been reported as $\mathrm{P}_{1}$ peak in $\mathrm{Fe}_{70} \mathrm{Pd}_{30}$ with and without BCT phase, and in $\mathrm{Fe}_{67} \mathrm{Pd}_{30} \mathrm{Co}_{3}$ and $\mathrm{Fe}_{66.8} \mathrm{Pd}_{30.7} \mathrm{Mn}_{2.5}$ without the appearance of BCT phase [2426]. The mechanism of the $P_{1}$ peak was related with a dislocation dragging mechanisms controlled by the migration of vacancies without break-away and is related to the intrinsic properties of the austenitic phase [25]. Therefore, the net peak height (after background subtraction) is lower in a matrix with BCT phase than in a matrix without BCT phase, since the BCT phase is still present overlapped to the austenite matrix. In fact, in FePdCo and FePdMn alloys a 32\% and 38\% (mass) transform to the BCT martensite during the cooling down to $170 \mathrm{~K}$, respectively. These amounts remain unless the alloy is annealed at high temperature and subsequently quenched [13]. After the first heating run up to $603 \mathrm{~K}$, the P1 peak decreases its height markedly in both alloys, indicating that the density of quenched-in-defects was decreased [24].

On the other hand, damping spectra show higher values of damping in martensitic phase than in austenitic phase. In fact, the damping behaviour out of the range of MT peak is controlled by the background damping values of each phase. This behaviour is in agreement with the damping capacity of the twin boundary and dislocations in the martensitic phase, while in the austenitic phase only dislocation contribute to background damping values. Nevertheless, the damping background values in the martensitic phase decrease, as different annealing were performed. This indicates that, effectively, the density of point defects and dislocations decreases and consequently the interaction between twin boundaries and structural defects decreases too. This effect is presented more clearly after the first heating run up to $603 \mathrm{~K}$ and $773 \mathrm{~K}$, so the maximum temperature was reached in consecutive cycles two times. Then, damping capacity in the martensitic phase decreases and the contribution to the damping values is mainly controlled by twin boundaries motion $[18,19]$.

Squared frequency curves, shown in Figures 4(b) and 5(b), exhibit the typical minimum at the MT temperature. At higher temperatures than the MT temperature, the modulus increases with the temperature accordingly with both the dragging mechanism (within the P1 peak temperatures) and the recovery of structure [25]. Moreover, a precipitation and decomposition processes of the $\gamma$ phase are present in the FePdMn alloy. Indeed, the increases of the MT peak after the annealing at $773 \mathrm{~K}$ in FePdMn (Figure 5(b)) 
was related with a mechanism that involves a precipitation and decomposition processes of the $\gamma$ phase [27].

The effect of the thermal cycles on the non-thermoelastic MT can be seen from the movement of the hillside towards lower temperatures in Figures 4(a) and 5(a). In fact, the FCT-BCT transition temperature moves towards lower temperatures mainly after the first thermal cycle at $603 \mathrm{~K}$. This behavior indicates that the reduction of structural defects difficult the appearance of BCT.
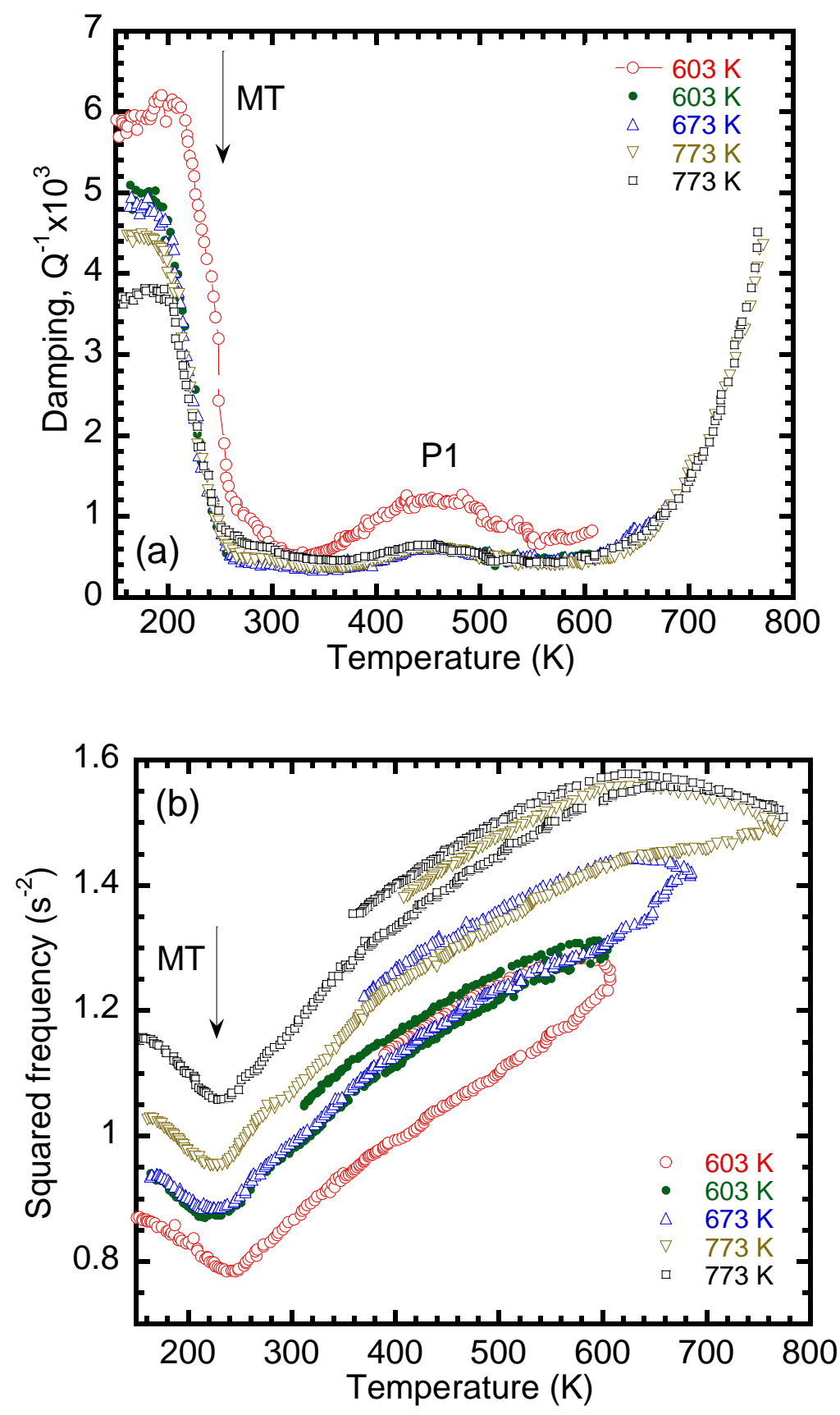

Figure 4: Damping spectra (a) and squared frequency curves (b) as a function of temperature during successive thermal cycles for a FePdCo alloy from $170 \mathrm{~K}$ up to different final temperatures. Lines are a guide for the eyes. 

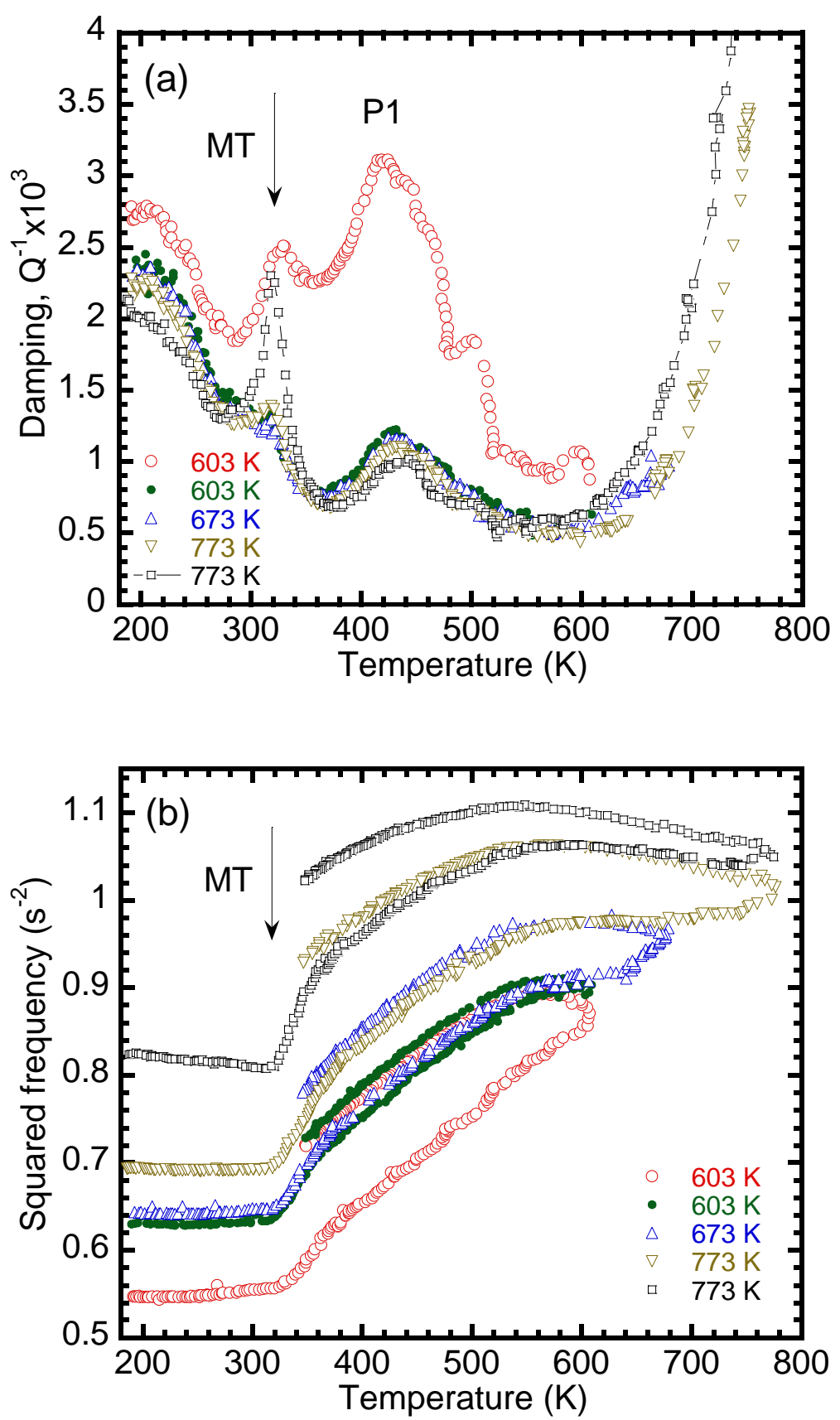

Figure 5: Damping spectra (a) and squared frequency curves (b) as a function of temperature during successive thermal cycles for a FePdMn alloy from $170 \mathrm{~K}$ up to different final temperatures. Lines are a guide for the eyes.

The appearance of ADD has been checked through the behaviour of S parameter for the first and second heating runs of the whole cycles shown in Figure 4 and $5 . \mathrm{S}$ values as a function of temperature for as-quenched samples and after annealing to $603 \mathrm{~K}$ is shown in Figure 6. As it can be expected, the values differ from zero for temperatures lower than MT temperature since the mobility of twin boundaries. The higher values of $\mathrm{S}$ for the annealed samples and the decrease of the amount of quenched-in-defects, i.e. decrease of P1 peak, indicate that both dislocations and variants increase their mobility. On the other hand, the $\mathrm{S}$ values are zero for temperatures higher than MT temperature. The absence of ADD effects indicate that the dislocation movement is carried out without thermally activated break-away [18-20,22,28].

Therefore, the appearance of the BCT phase and the addition of substitutional atoms no modifies the mechanisms of the peak $\mathrm{P}_{1}$. Nevertheless, additional little peaks appear superimposed to $\mathrm{P}_{1}$ peak. These little peaks could be related with the interaction of substitutional atoms with the BCT phase retained in the $\gamma$ phase. 


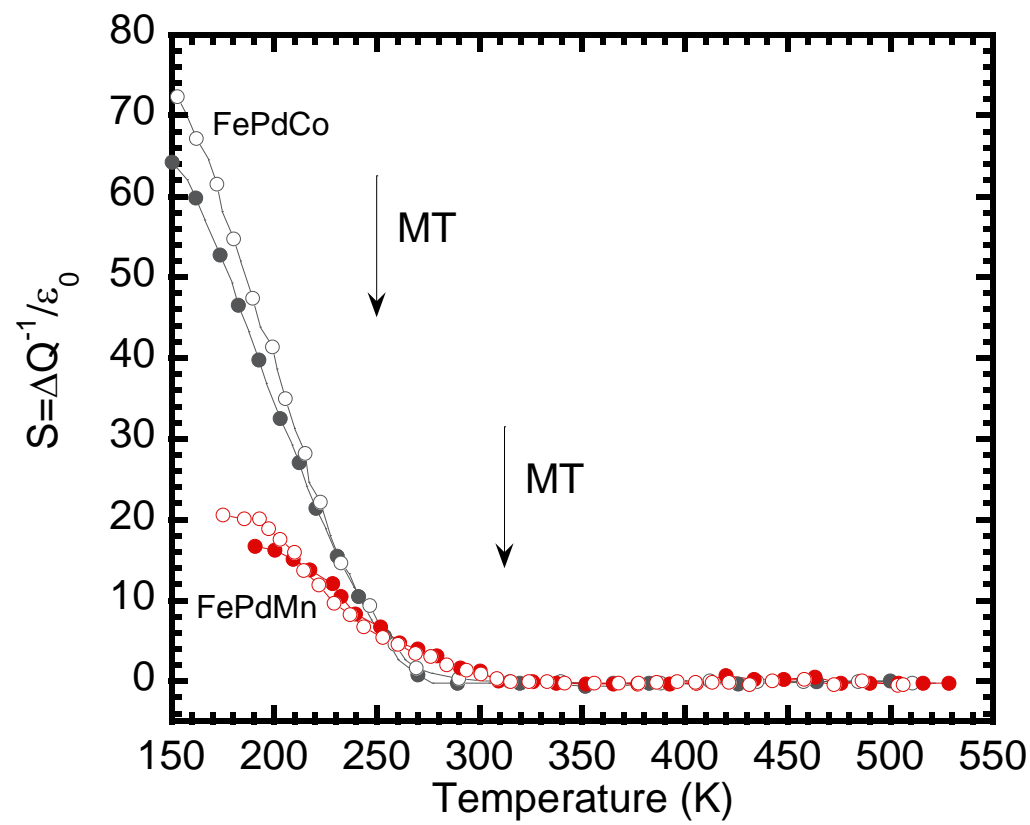

Figure 6: $\mathrm{S}$ parameter as a function of temperature for the as-quenched (circles) and annealed at $603 \mathrm{~K}$ (open circles) state for a FePdCo and FePdMn alloys. Lines are a guide for the eyes.

Finally, in order to check that both the non-thermoelastic MT transition and the Mn and Co substitutional atoms have not influence on the relaxation mechanism controlling $\mathrm{P}_{1}$ peak, the activation energy and pre-exponential factor for the relaxation time corresponding to $\mathrm{P}_{1}$ peak were obtained from the Arrhenius plot (the peak temperature shifts measured at different oscillation frequencies) for both alloys [18]. In fact, Figure 7 shows the Arrhenius plot related to $\mathrm{P}_{1}$ peak for the two alloys. The values obtained were $\mathrm{Ha}_{\mathrm{FePdCo}}=(1.0 \pm 0.1) \mathrm{eV}$ and $\tau_{\mathrm{oFePdCo}}=8 \cdot 10^{-(14 \pm 0.5)} \mathrm{s}$, and $\mathrm{Ha}_{\mathrm{FePdMn}}=(1.0 \pm 0.1) \mathrm{eV}$ and $\tau_{\mathrm{oFePdMn}}=1 \cdot 10^{-(13 \pm 0.5)} \mathrm{s}$. These values are in agreement with those previous obtained in these alloys, FePdCo and FePdMn, without the appearance of the BCT phase [24]. Moreover, the activation parameters are also in agreement with previous reported works in $\mathrm{Fe}_{70} \mathrm{Pd}_{30}$ with and without the appearance of the BCT phase [24,25]. Consequently, the driving force controlling the development of $\mathrm{P}_{1}$ is effectively the same as said before [25].

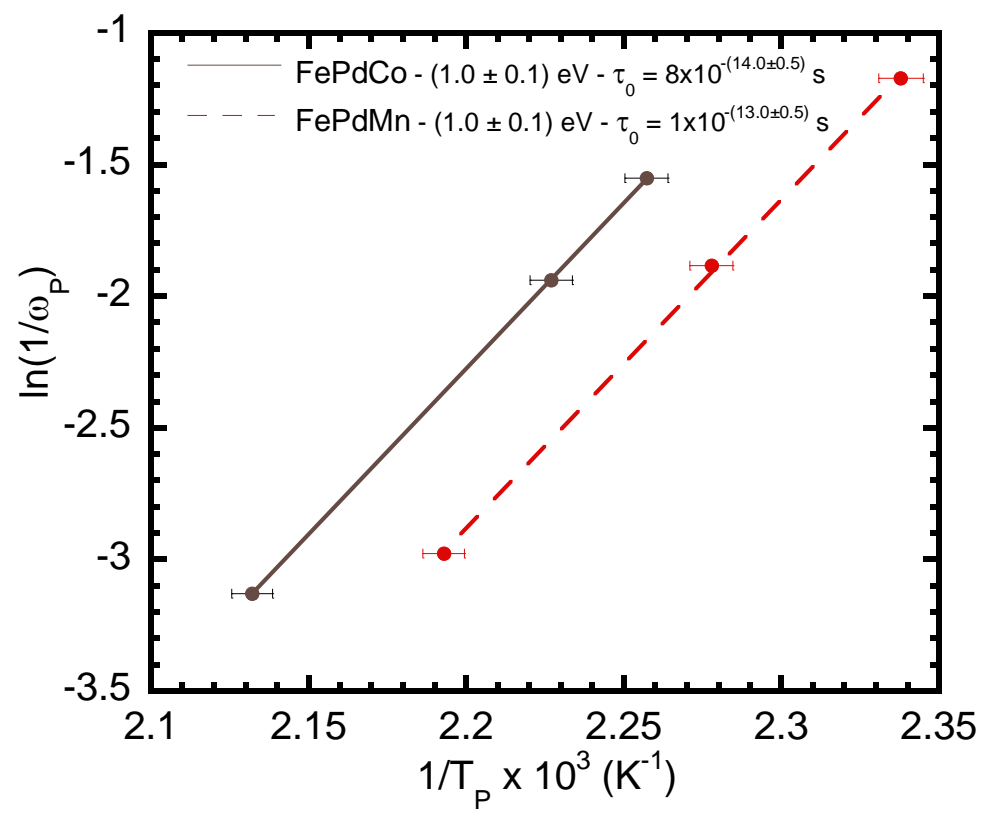

Figure 7: Arrhenius plot for FePdCo and FePdMn alloys related to $\mathrm{P}_{1}$ peak. 
Therefore, the behaviour of the P1 peak let to conclude that annealing of FePdCo and FePdMn alloys over $603 \mathrm{~K}$ leads to a recovery of the structure where the amount of point defects and dislocations decrease. So, it is expected that this recovery makes difficult the accommodation of the misfit strain between the FCT and the BCT phases, giving rise to a decrease in the temperature for the appearance of the irreversible BCT phase [25]. In fact, from Figures 4(a) and 5(a) it can be seen the movement of the hillside of the MT nonthermoelastic phase at lower temperatures, between $210 \mathrm{~K}$ and $250 \mathrm{~K}$ for FePdCo and between $200 \mathrm{~K}$ and $290 \mathrm{~K}$ for FePdMn. This movement of the hillside is directly related with the movement towards lower temperatures of the FCT-BCT transition. Indeed, Figure 8 shows a decrease in the temperature for the appearance of the BCT phase measured through DSC in $\mathrm{Fe}_{70} \mathrm{Pd}_{30}$ (full line) and MS in $\mathrm{Fe}_{70} \mathrm{Pd}_{30}$ (dashed line) [25], $\mathrm{Fe}_{67} \mathrm{Pd}_{30} \mathrm{Co}_{3}$ (dotted line) and $\mathrm{Fe}_{66.8} \mathrm{Pd}_{30.7} \mathrm{Mn}_{2.5}$ (alt-dashed line); from where a good correspondence between the curves can be observed.

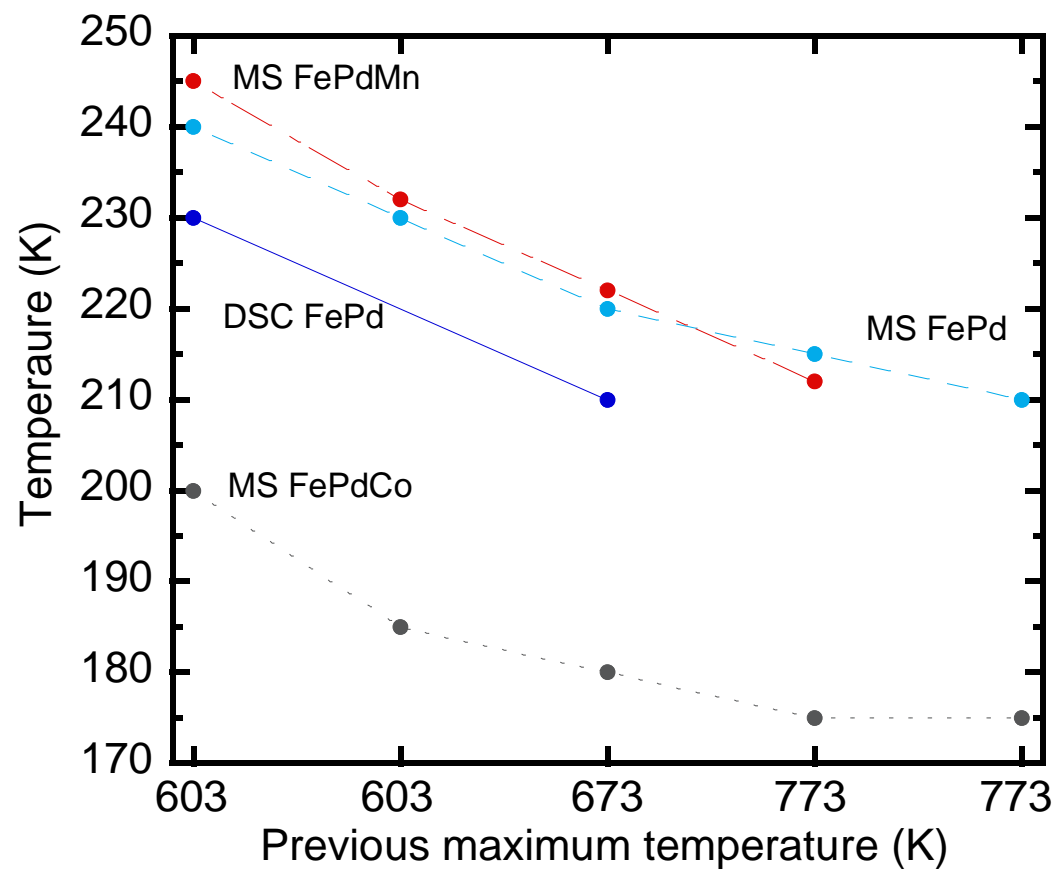

Figure 8: FCT-BCT transformation temperature as a function of the maximum temperature of the thermal cycles. See explanation in the text.

\section{CONCLUSIONS}

The stability at low temperatures of the thermoelastic martensite in FePdCo and FePdMn alloys is restricted by the irreversible FCT-BCT phase transformation. The appearance of dislocations, as a result of the FCTBCT strain misfit, and their dynamics has been analyzed by mechanical spectroscopy. The P1 damping peak, at around $450 \mathrm{~K}$, related to the dislocation movement has been identified in these alloys with BCT nonthermoeleastic MT. The appearance of non-thermoeleastic MT and the addition of substitutional atoms do not modify the physical mechanisms controlling the P1 peak. Moreover, the behavior of the movement of the FCT-BCT transition temperature is not affected by the addition of substitutional atoms. Finally, a reduction of the dislocation density reduces the irreversible transformation temperature and so, increases the stability range of the FCC-FCT reversible transformation.

\section{ACKNOWLEDGMENTS}

This work has been carried out with the financial support of the Spanish "Ministerio de Ciencia $y$ Tecnología" (Project number MAT2012-37923), the CONICET-PIP 2098 and 0179, and the PID-UNR; ING 453 (2014-2017). Authors also wish to acknowledge to the Cooperation Agreement between the Universidad Pública de Navarra and the Universidad Nacional de Rosario, Res. 5789/2013 and Res. 3247/2015. 


\section{BIBLIOGRAPHY}

[1] ULLAKKO, K., HUANG, J.K., KANTNER, R.C., et al., "Large magnetic-field-induced strains in Ni2MnGa single crystals", Applied Physics Letters, v. 69, n. 13, pp. 1966-1968, 1996.

[2] MA, J., KARAMAN. I., "Expanding the repertoire of shape memory alloys", Science, v. 327, n. 5972, pp. 1468-1469, 2010.

[3] MATSUI, M., YAMADA, H., ADACHI, K., "A new low temperature phase (fct) of Fe-Pd invar" Journal of the Physical Society of Japan, v. 48, n. 6, pp. 2161-2162, 1980.

[4] SOHMURA, T., OSHIMA, R., FUJITA, F.E., "Thermoelastic FCC-FCT martensitic transformation in Fe-Pd alloy", Scripta Metallurgica, v. 14, n. 8, pp. 855-856, 1980.

[5] OSHIMA, R., SUGIYAMA, M. "Martensite transformations in Fe-Pd alloys", Le Journal de Physique Colloques IV, v. 43(C4), pp. C4-383, 1982.

[6] SUGIYAMA, M., OSHIMA, R., FUJITA, F.E., "Martensitic transformation in the Fe-Pd alloy system", Transactions of the Japan institute of metals, v. 25, n. 9, pp. 585-592, 1984.

[7] CUI, J., SHIELD, T.W., JAMES, R.D., "Phase transformation and magnetic anisotropy of an ironpalladium ferromagnetic shape-memory alloy”, Acta Materialia, v. 52, n. 1, pp. 35-47, 2004.

[8] SUGIYAMA, M., HARADA, S., OSHIMA, R., "Change in young's modulus of thermoelastic martensite Fe-Pd alloys" Scripta metallurgica, v. 19, n. 3, pp. 315-317, 1985.

[9] SUGIYAMA, M., OSHIMA, R., FUJITA, F.E., "Mechanism of FCC-FCT Thermoelastic Martensite Transformation in Fe-Pd Alloys", Transactions of the Japan institute of metals, v. 27, n. 10, pp. 719-730, 1986.

[10] MUTO, S., OSHIMA, R., FUJITA, F.E., "Elastic softening and elastic strain energy consideration in the fcc-fct transformation of Fe抟 Pd alloys", Acta Metallurgica et Materialia, v. 38, n. 4, pp. 685-694, 1987.

[11] TANAKA, K., OSHIMA, R., "Role of Annealing Twin in the Formation of Variant Structure of bct Martensite in Fe-Pd Alloy", Materials Transactions, JIM, v. 32, n. 4, pp. 325-330, 1991.

[12] OSHIMA, R., MUTO, S., FUJITA, F.E., "Initiation of FCC-FCT thermoelastic martensite transformation from premartensitic state of Fe-30 at\% Pd alloys", Materials Transactions, JIM, v. 33, n. 3, pp. 197-202, 1992.

[13] SÁNCHEZ-ALARCOS, V., PÉREZ-LANDAZÁBAL, J.I., RECARTE, V., "Effect of Co and Mn Doping on the Martensitic Transformations and Magnetic Properties of Fe-Pd Ferromagnetic Shape Memory Alloys", Materials Science Forum, v. 635, pp. 103-110, 2010.

[14] SÁNCHEZ-ALARCOS, V., RECARTE, V., PÉREZ-LANDAZÁBAL, J.I., et al., "Effect of Mn addition on the structural and magnetic properties of Fe-Pd ferromagnetic shape memory alloys", Acta Materialia, v. 57, n. 14, pp. 4224-4232, 2009.

[15] MURA, T. Micromechanics of defects in solids, New York, USA, Martinus Nijhoff Publishers; 1987.

[16] SHIBATA, M., ONO, K., "The strain energy of a spheroidal inclusion and its application to bcc-hcp martensitic transformation”, Acta Metallurgica, v. 23, n. 5, pp. 587-597, 1975.

[17] LAGOUDAS, D.C., ENTCHEV, P.B., POPOV, P., et al., "Shape memory alloys, Part II: Modeling of polycrystals", Mechanics of Materials, v. 38, n. 5, pp. 430-462, 2006.

[18] SCHALLER, R., FANTOZZI, G., GREMAUD. G. (eds.), Mechanical Spectroscopy. Switzerland, Trans. Tech. Publ. Ltd, 2001.

[19] FRIEDEL, J., Dislocations, Reading, Addison-Wesley, 1967.

[20] LAMBRI, O.A. "A review on the problem of measuring nonlinear damping and the obtainment of intrinsic damping”, In: Martinez-Mardones, J., Walgraef, D., Wörner, C.H. (eds.), Materials Instabilities. New York, USA, World Scientific Publishing Co Pte Ltd, 2000.

[21] LAMBRI, O.A. "Intensidad de Relajación en Materiales con Estructura Cúbica Centrada en el Cuerpo", Ph.D. Thesis, Universidad Nacional de Rosario, Argentina, 1993.

[22] MOLINAS, B.J., LAMBRI, O.A., WELLER, M., "Study of non-linear effects related to the SnoekKöster relaxation in Nb", Journal of alloys and compounds, v. 211, pp. 181-184, 1994.

[23] SÁNCHEZ-ALARCOS, V., RECARTE, V., PÉREZ-LANDAZÁBAL, J. I., et al., "Reversible and irreversible martensitic transformations in Fe-Pd and Fe-Pd-Co alloys", The European Physical Journal Special Topics, v. 158, n. 1, pp. 107-112, 2008. 
[24] BONIFACICH, F.G., LAMBRI, O.A., PÉREZ-LANDAZÁBAL, J.I., et al., "Mobility of Twin Boundaries in Fe-Pd-Based Ferromagnetic Shape Memory Alloys", Materials Transactions, JIM, v. 57, n. 10, pp. 1837-1844, 2016.

[25] PÉREZ-LANDAZÁBAL, J.I., LAMBRI, O.A., BONIFACICH, F.G., et al, "Influence of defects on the irreversible phase transition in Fe-Pd ferromagnetic shape memory alloys", Acta Materialia, v. 86, pp. 110$117,2015$.

[26] BONIFACICH, F.G., LAMBRI, O.A., RECARTE, V., et al., "Espectroscopía Mecánica en Aleaciones Magnéticas con Memoria de Forma de FePd dopadas con Mn y Co", In: Proceedings of the Congreso Internacional de Metalurgia y Materiales SAM-CONAMET / IBEROMAT 2014, Santa Fe, Argentina, 2014.

[27] BONIFACICH, F.G., PÉREZ-LANDAZÁBAL, J.I., LAMBRI, O.A., et al., "Modification of the austenite finish upon thermal treatments in Fe-Pd-Mn ferromagnetic shape memory alloy", Materials Science and Engineering A, v. 683, pp. 167-171, 2017.

[28] GRANATO, A. V., LÜCKE, K., "Theory of mechanical damping due to dislocations", Journal of applied physics, v. 27, n. 6, pp. 583-593, 1956. 